\title{
EL ESCRITOR PERIÓDICO: LEOPOLDO ALAS CLARÍN, 1883-1884
}

\author{
SANTIAGo Díaz LAGE \\ Universidade de Santiago de Compostela
}

\section{CRISIS DE LA ESCRITURA}

Los años de 1882 a 1884 ven la primera ascensión y la primera caída del periodista Leopoldo Alas Clarín, desde su reconocida participación en el debate sobre el Naturalismo, hasta el momento en que se encuentra sin «una almena que pueda decir que es mía», sin ninguna hoja «donde decir mi leal opinión» ${ }^{1}$. Lo paradójico del caso es que este proceso coincide en el tiempo con la expansión de la prensa registrada a lo largo de la década de 1880, cuando empiezan a aparecer nuevos diarios, semanarios culturales, revistas ilustradas $\mathrm{y}$, con ellos, toda clase de suplementos especializados y almanaques $^{2}$. Leopoldo Alas, entregado a la construcción de una figura pública, consagrado como crítico literario ya antes de publicarse Solos de Clarín en 1881 , no perderá la ocasión de prodigarse en esos medios recién fundados, conjugando distintas periodicidades y buscando distintos cauces para cada una de las formas enunciativas que cultiva ${ }^{3}$. Pero, al hacerlo, se verá en la nece-

\footnotetext{
${ }^{1}$ La primera cita procede de una carta a Galdós fechada el 24 de julio de 1884, en Soledad ORTEGA (ed.), Cartas a Galdós, Madrid: Revista de Occidente, 1964, pp. 221223 , p. 223; la segunda, de la carta sin fecha que la precede, pp. 218-221, p. 220.

2 Véase, a título indicativo, Jean-François BOTREL, «Estadística de la prensa madrileña de 1858 a 1909», en Libros, Prensa y Lectura en la España del siglo XIX, Madrid: Fundación Germán Sánchez Ruipérez-Editorial Pirámide, 1993, pp. 360-379; y Cecilio ALONSO, «Clarín y la configuración del espacio literario en la prensa de la Restauración», en Araceli Iravedra VAlEA, Elena DE LORENZo Álvarez y Álvaro RUIZ DE LA PEÑa (eds.), Leopoldo Alas, Un clásico contemporáneo: Actas del congreso celebrado en Oviedo (12-16 de noviembre de 2001), Oviedo: Universidad de Oviedo, 2002, pp. 157-201.

${ }^{3} \mathrm{Si}$ en 1881 escribe, con una u otra firma, para La Publicidad, El Mundo Moderno, El Progreso, El Imparcial y El Día, en 1883 ya colabora periódicamente en El Día, La Publicidad, El Guadalete, El Porvenir de Sevilla, La Ilustración Ibérica, Arte y Letras, El Progreso, Madrid Cómico y La Diana, y más ocasionalmente en La Ilustración Española y Americana, La Ilustración Artística, La Revista Ibérica y en el Almanaque de la Ilustración (para 1884): cfr. Yvan LISSORGUES, «La producción periodística de Leopoldo
}

Rlit, LXVII, 134 (2005), 411-439 
sidad de ajustar su escritura a una lógica de producción de texto y unas condiciones de publicación que ya no son las de su época de redactor en $E l$ Solfeo y en La Unión, sino las de un escritor periódico que, más que obrero literario, como querría la ortodoxia naturalista, acabará por ser empresario de sí mismo ${ }^{4}$.

El escritor periódico es aquel que, para procurarse unos ingresos y mantener un cierto margen de libertad creativa, empieza a colaborar en distintas revistas y diarios, vendiéndole a cada uno de ellos, según su carácter y su naturaleza, un género de texto más o menos especializado; junto a la perspectiva tantas veces imaginada de dirigirse a distintas fracciones sociales surge, pues, la posibilidad real de dirigirse a distintos momentos de una misma fracción social. Pero al dispersarse la presencia pública del escritor en varios periódicos, se espacian también sus intervenciones en cada uno de ellos, de modo que el principio y el final de cada enunciado quedan mucho más marcados y jerarquizados, y la conciencia de estar diciendo algo, de deber decirlo, o de no decirlo cuando debería decirse, llega con frecuencia a revelarse en el discurso: con la expansión capitalista de la prensa, la palabra pública se vuelve al mismo tiempo más banal y más irreversible 5 .

El desarrollo de la escritura periódica, en tanto que modo de producción de texto, se asienta sobre dos fenómenos complementarios: uno, la disgregación de la plana de los periódicos en formas textuales cada vez más breves y heterogéneas; y dos, el éxito paralelo de los suplementos semanales concebidos según el modelo de Los lunes de El Imparcial, que acogían, bajo una forma periódica, los tipos de texto que no cabían en el diario, ocupando así un espacio que hasta entonces estaba reservado a las revistas ilustradas. Tan dispares son las voces que conforman la lectura diaria, semanal o mensual de un lector cada vez más anónimo, que los escritores buscarán técnicas para tender un hilo textual que atraviese tantos retazos de cotidianeidad y construya, también en el hábito de leer el periódico, una memoria de lo que se dijo aquí mismo días, semanas o meses antes. Quizás por eso las técnicas de nuestros escritores periódicos tratan, ya no sólo de conferirle al texto una continuidad argumental o argumentativa que no tuvo ni en la concepción ni en la escritura, sino más bien de restituirle al escritor, mediante el texto, una imagen unitaria y coherente de sí mismo y de su actividad. El carácter

Alas, Clarín (1868-1901)», en Leopoldo AlAS Clarín, Obras completas VII: Artículos (1882-1890), ed. Jean-François Botrel e Yvan Lissorgues, Oviedo: Nobel, 2004, pp. 7-57.

${ }^{4}$ Remito aquí a Émile ZoLA, «L'argent dans la littérature» [1880], en Le Roman Expérimental, Paris: Garnier-Flammarion, 1971, pp. 175-210. Cfr. Jean-François BotReL, «Zola, l'argent et la condition de l'écrivain en Espagne», en Simone SAILlard y Adolfo SOTELO VÁZQUEZ (eds.), Zola y España: Actas del coloquio internacional (Lyon, septiembre de 1996), Barcelona: Edicions de la Universitat de Barcelona, 1997, pp. 35-43.

${ }^{5}$ Cfr. Mijail M. BAJTín, «El problema de los géneros discursivos», en Estética de la creación verbal, México: Siglo XXI, 1997 (7ª ed.), pp. 248-293, especialmente pp. 256-270. 
social de la escritura queda separado del escritor, como si fuese un don natural social del propio texto.

En los años 1883 y 1884, toda la escritura de Leopoldo Alas Clarín parece estar atravesada por estas problemáticas teóricas y prácticas, y de ello tenemos pruebas tanto en su correspondencia como en los textos periodísticos que me propongo analizar aquí, a saber, las cartas de El hambre en Andalucía-La crisis de Andalucía y los cuentos de Los transeúntes, «Avecilla» y «Bustamante». Esos tres títulos representan en total treinta y nueve entregas, es decir, treinta y nueve unidades de escritura, publicación y retribución ${ }^{6}$ las veintiuna de El hambre en Andalucía se publican en El Día entre el 31 de diciembre de 1882 y el 21 de julio de 1883; las once que constituyen «Avecilla» aparecen en La Ilustración Ibérica entre el 6 de enero y el 6 de septiembre de 1883; y las siete de «Bustamante» empiezan a publicarse el 10 de abril y terminan el 27 de diciembre de 1884, poco antes de salir «Zurita» en el Almanaque de la Ilustración Española y Americana para 1885. A lo largo de 1883 habían ido entreverándose en la prensa, desde La Ilustración Artística hasta Madrid Cómico, «El amigo del drama», «Mi entierro (Discurso de un loco)», «Los señores de Casabierta» y «Palomares I (Fragmento de una novela): Mosquín», y muchos de los cuentos que después aparecerían en Pipá (1886) 7 . Al prepararlos para la edición en libro, a finales de 1885, Alas insistió en datar los textos, "para que se vea que todo es anterior a $L a$ Regenta ${ }^{8}$, como si ya quisiera acotar en su trayectoria una etapa coherente en la que el crítico literario y político va haciéndose novelista.

¿Qué puede significar tal dedicación a la narrativa? Está claro que entre 1882 y 1884 Alas utiliza sus colaboraciones en prensa como banco de pruebas de ideas, técnicas y personajes que desarrollará y utilizará en La Regenta ${ }^{9}$.

\footnotetext{
${ }^{6}$ Para la distinción de título, artículo y entrega, véase Yvan LisSORGUES, op. cit., p. 13.

7 Tomo los datos de los cuadros cronológicos que incluye Carolyn RichmOND en su edición de los Cuentos completos de Clarín, Madrid: Alfaguara, 2000, tomo II/2, pp. 617-625.

${ }^{8}$ De una carta a Manuel Fernández Lasanta, sin fecha pero contestada por este el 4XII-1885, en Josette BLANQUAT y Jean François BOTREL, Clarín y sus Editores: 65 cartas inéditas de Leopoldo Alas a Fernando Fe y Manuel Fernández Lasanta, 1884-1893, Rennes: Université de Haute Bretagne, 1981, pp. 19-21, p. 20.

9 Véase Simone SAILlARD, «Leopoldo Alas, 1882-1884: el tiempo de La Regenta», en Juan José GIL Cremades y Leonardo Romero Tobar (eds.), Clarín, catedrático de Zaragoza, Zaragoza: Prensas Universitarias, 2001, pp. 121-143; y Leopoldo Alas (Clarín), collaborateur du journal El Día.-Du journalisme au roman, Thèse de Doctorat d'État, Université de Toulouse-Le Mirail, 1974. Cfr. también Sergio BESER, «Introducción», en Sergio BESER (ed.), Clarín y «La Regenta», Barcelona: Ariel, 1982, pp. 9-93; Leonardo ROMERO TOBAR, «La etapa zaragozana de Clarín: biografía y creación literaria», en Juan José Gil Cremades y Leonardo Romero Tobar (eds.), pp. 77-93; Carolyn RichmOND, «Conexiones temáticas y estilísticas del libro Pipá con La Regenta», en Antonio VILANOVA (ed.), Actas del Simposio Internacional «Clarín» y su obra en el Centenario de La Regenta, Barcelona: Edicions de la Universitat de Barcelona, 1985, pp. 229-250, y «Gérmenes de La Regenta en tres cuentos de Clarín», en Actas del VIII Congreso de la Asocia-
} 
Pero, al mismo tiempo, la producción de textos de ficción reacciona a la crisis de escritura que he mencionado, e intenta conjurarla por dos vías: por un lado, el argumento, la situación e incluso los nombres de los personajes pueden cohesionar el discurso, encarnando en el texto final la unidad perdida del trabajo intelectual, la redacción, los distintos momentos de la publicación, y la lectura; por otro, la ficción no genera necesariamente un sustrato de documentos que pueda dificultar o diferir la puesta en frases del original definitivo, sino que desde el principio pone en circulación pública toda la letra. Si la realización de un artículo-cuento ${ }^{10}$ es, para Clarín, un ejercicio de memoria que cobra forma en el acto mismo de escribir una entrega destinada a la publicación, la de una encuesta económica como El hambre en Andalucía está atravesada por un intrincado trasfondo de datos, cifras, documentos y testimonios anteriores al momento de la escritura, que son también abstracciones y cuantificaciones de realidades sociales que el enviado especial vio, interpretó y racionalizó ${ }^{11}$. Aunque las primeras cartas fueron redactadas durante el viaje, el proceso general de producción de texto queda escindido en dos momentos tendentes a autonomizarse el uno del otro: el de la recolección de datos y cifras, que se realiza en contacto con la realidad de la que se habla, y el de la redacción a posteriori del original, en el que han de reconciliarse la memoria y los números obtenidos.

Esta particularidad se revela incompatible con las técnicas de escritura discontinua que Alas usa para sus textos de ficción, en la medida en que incluso su plan de trabajo parece excluir, o al menos desaconsejar, todo atisbo de improvisación. De las condiciones y determinaciones que ello impone, de las dificultades prácticas a las que se enfrenta Alas en El hambre en Andalucía y en Los transeúntes, de los tropos ideológicos con que les da consistencia a sus textos, de la lógica económica que domina la escritura periódica, quiere tratar el presente trabajo.

ción Internacional de Hispanistas, vol. II/2, Madrid: Istmo, 1986, pp. 499-506; y Gonzalo Sobejano, Clarín en su obra ejemplar, Madrid: Castalia, 1985, pp. 77-91.

${ }^{10}$ Sobre el uso de este término, véase José Manuel GonZÁlEZ HERRÁN, "Artículos'/ 'cuentos' en la literatura periodística de Clarín y Pardo Bazán», en Luis F. DíAz LARIOS et al., La elaboración del canon en la literatura española del siglo XIX: II Coloquio de la Sociedad de Literatura Española del siglo XIX (Barcelona, 20-22 de octubre de 1999), Barcelona: Publicacions de la Universitat de Barcelona-PPU, 2002, pp. 209-227.

11 Véase el estudio preliminar de Simone SAILlaRd a su edición de Leopoldo Alas Clarín, El hambre en Andalucía, Toulouse: Presses Universitaires du Mirail, 2001, pp. 15140. Sigo siempre esta edición, indicando entre paréntesis en el cuerpo del texto, en números romanos, la carta donde se encuentra la cita y, en números arábigos, la página correspondiente. Sobre lo que digo de la escritura de Clarín, véase Jean-François BOTREL, «En el taller de Clarín: de la cuartilla a la página», Turia 57 (2001), pp. 151-163. 


\section{LA VOZ DEL CONTRIBUYENTE}

Durante su viaje por Andalucía, el enviado especial de El Día se molestó en consultar a personas «aficionadas a los estudios económicos» (VI, p. 168), «personas imparciales» (II, p. 153) y «muy autorizadas» (III, p. 155), «que conocen el pueblo» (IV, p. 160) y «que por razón de su oficio se ven en continuo contacto con la clase obrera» (IV, pp. 161-162), para recopilar, ordenar y sistematizar «lo que por fuerza de la lógica tenemos que aceptar todos: los hechos» (I, p. 147). A través de las palabras de sus informantes $\mathrm{y}$, sobre todo, a través de los datos y las cifras que le proporcionan, Alas intentará interiorizar en su presencia pública todas las diferencias de una realidad social vivida, aunque ajena, y construir un discurso que, sin caer en la escritura genérica, produzca un efecto de objetividad e imparcialidad. Estos testimonios serán la expresión de los «hechos» que constituyen el principal punto de encuentro entre el periódico y el corresponsal, pero también la sombra de una figura que articula, cual protagonista colectivo y anónimo, todo el texto de El hambre en Andalucía: la figura del contribuyente.

En un artículo publicado en La Publicidad el veinticinco de enero de 1882, o sea apenas dos meses después de su primera colaboración en El Día, Clarín les presenta el siguiente dilema a sus lectores: «ser o no ser contribuyente; ésta es la cuestión. Si soy contribuyente algo tengo que ver con el Estado, algo me toca del Estado a mí, aunque no me toque nada de nómina» ${ }^{12}$. Si en abril de 1880 hablaba de «los pacíficos bueyes que son a los toros lo que los contribuyentes a los políticos activos» ${ }^{13}$, ahora contempla la contribución como una relación específica del ciudadano con el Estado, es decir, como una vía de participación política que, tras verse reducida a la esfera privada de la economía doméstica, intenta adquirir una cierta visibilidad pública. En El hambre en Andalucía la imagen del contribuyente y la lógica de la contribución forman un ideologema singularmente ambivalente, que efectúa la mediación entre las esferas desgajadas de la economía y la política, entre la vida pública y la vida privada ${ }^{14}$ : en cuanto que grava sobre todo a las numerosas clases medias y a la pequeña burguesía, la contribución aparece

\footnotetext{
12 «Palique» [La Publicidad, 25-I-1882], en Leopoldo Alas Clarín, Obras completas VI: Artículos (1879-1882), ed. Jean-François Botrel e Yvan Lissorgues, Oviedo: Nobel, 2003, pp. 832-835, p. 833.

${ }^{13}$ La cita procede de «Ecos y Rumores» [Revista de Asturias, 15-V-1880], en Obras completas VI: Artículos (1879-1882), pp. 475-478, p. 475. Véase también el «Palique» [18XI-1881] que inaugura la colaboración de Clarín en El Día, ibid., pp. 761-763: «igual que en los dramas morales muere siempre el traidor, en el teatro político quien la paga... es el contribuyente. Ese comparsa» (p. 763).

${ }^{14}$ Para el concepto de ideologema, véase Valentin N. Voloshinov, El marxismo y la filosofía del lenguaje (Los principales problemas del método sociológico en la ciencia del lenguaje), Madrid: Alianza Editorial, 1992, pp. 31-50.
} 
como imagen económica complementaria de la imagen política del sufragio universal, y las corruptelas fiscales y ocultaciones, tantas veces denunciadas en El Día, vienen a ser la imagen económica del caciquismo ${ }^{15}$. Quizás obligado por los términos de su contrato, Alas trata de construir en torno a ella una posición que no es estrictamente la suya propia, sino más bien la de sus informantes andaluces y la de Camilo Hurtado de Amézaga y Balmaseda, marqués de Riscal y propietario de El Día: de ellos proceden los datos y las cifras, muchas impresiones y rumores de los que Alas se hace eco, y hasta fragmentos literales de su discurso ${ }^{16}$. De ese extrañamiento del escritor ante su material derivan, como veremos a continuación, no pocas de las dificultades técnicas con las que habrá de enfrentarse en el proceso de producir su texto.

¿Quién estaría en condiciones de exigir responsabilidades ahora que «el Estado y la iniciativa individual pueden y deben mirar de frente, y en su totalidad y con madura reflexión, esta cuestión pavorosa que Andalucía nos presenta» (I, p. 150)? La primera vez que delimita un sujeto para ese proceso histórico en crisis, Alas habla en general de «el Gobierno y cuantos deben procurar algo en favor de Andalucía», y les atribuye la tarea «de estudiar el terrible problema y buscar remedios duraderos y justos para tantos males» (I, pp. 149-150); frente a ellos aparece un hambre apenas personificada, simple objeto de las medidas que debieron tomarse y no se tomaron: «cuando el hambre era tal que salía al paso a los caminos, entraba a las tahonas a coger el pan, convertía en gritos de motín los ayes de sus dolores, los remedios tenían que ser paliativos, eran conquistas, y la forma cualquiera» (I, p. 150). El contribuyente, los almacenistas y los viñistas encarnan así

${ }^{15}$ Incluso el intervencionismo económico y el caciquismo quedan imbricados por vía negativa en las ocultaciones: «Caer en el pesimismo en que caen algunos, librando de responsabilidad a todas las autoridades y diciendo que el mal no tiene remedio, porque nace de vicios invencibles en la raza, de decadencia, o por lo menos, estancamientos inevitables, como es inevitable la vejez en los organismos físicos, es olvidar los hechos que están diciendo a gritos que muchos de los males nacen de errores visibles, ajenos a estas tristes consideraciones etnológicas, v. gr., si en un pueblo como Jerez hay tal desigualdad en la tributación, que se vió [sic] ocupando el octavo lugar en la lista jerárquica de contribuyentes, hombres que no tenían para pagar su entierro, y muy por debajo de él quien podía enterrar a todos los jerezanos, ¿se podrá atribuir esto a vicios fisiológico-morales de la raza? [...] Pues ni el gobierno piensa en castigar estos delitos [las ocultaciones] ni la opinión los mira con todo el odio que debiera. A mí me consta que a disposición del ministerio de Hacienda estuvieron años y años (y en rigor en su poder están siempre) los datos que pueden ilustrarle en este punto, datos que, casi con los números y sus relaciones, están diciendo los nombres de los que ocultan riqueza territorial; y la Hacienda nada ha hecho, porque, como todo se da la mano en la vida social, para mal como para bien, los mismos que tienen interés en que esa clase de delitos no se persiga, son personajes influyentes en la Administración y en la política: hay diputados, hay grandes dignitarios [sic] que verían su nombre en la lista de los grandes ocultadores, el día feliz y de justicia en que esa lista se publicara» (VI, pp. 167-170).

${ }^{16} \mathrm{Cfr}$. Simone SAILlaRD, «Estudio preliminar», 15-30 y 61-74. 
a toda una sociedad contrapuesta a las dos únicas clases que reciben tal nombre, que son la clase obrera o jornalera y la clase exportadora (recordemos la distinción entre esta y los «almacenistas y viñistas» que se planteaba en la «Carta» número catorce). Mientras que las clases tienen una articulación institucional que las ampara y les concede una cierta visibilidad política, el contribuyente es la víctima silenciosa de todas las culpas y todos los errores: con sus impuestos enriquece a un Estado que después encubre y favorece descaradamente a sus competidores, y cava su propia tumba aportando los fondos necesarios para sostener a la clase obrera con salarios municipales que no corresponden ni a la realidad del mercado ni al precio del trabajo.

Entre estos elementos desgajados, tomados como encarnaciones de los principios de la economía política y la estadística, no existe mediación alguna, y Alas se atribuye la misión de conciliarlos en un «estudio sereno y serio de una enfermedad real, que es preciso atacar, no por el prurito de atacar a nadie, sino porque no hay otro camino para procurar el adecuado remedio» (II, p. 154). La culpa común y los errores que a nadie son ajenos propagan, como una imagen refleja, la idea de que existe un interés social general, y la prensa se arroga la función política específica de mediar entre el Estado y unas clases que se quieren encarnación indiferenciada de toda la sociedad: «ojalá el débil concurso de este trabajo que emprende El Día, pueda servir de algo, poco que sea, a la gran obra, que debe ser común, como lo es el interés de que se trata» (I, p. 150); «no es la prensa la que debe olvidar que con la fuerza sólo se puede remediar el mal que se haga por la fuerza» (VII, p. 172); «ayudar a esos notables de su tierra a hacer memoria, es a lo que deben dirigirse los conatos de la prensa ilustrada; no sólo a satisfacer con narraciones de impresión la curiosidad del público nervioso» (VII, p. 174).

La prensa se presenta, en suma, como un poder verdaderamente autonomizado que tratará de «ilustrar una materia difícil, de cuya solución práctica están principalmente encargados el gobierno y los distintos poderes, según su esfera de acción propia» (VIII, p. 176): se trata de abrir un espacio ideológico donde pueda ejercerse «la presión de la opinión pública, irresistible cuando se pronuncia» ${ }^{17}$. Alas da una imagen muy clara de las implicaciones prácticas de este proyecto cuando le atribuye a su trabajo la función de hacer reflexionar y de enseñar al «observador», que ya no es tan sólo un ciudadano activo y responsable que se interesa por lo que la ideología burguesa del momento llamó la cuestión social, sino también el «spectateur d'un drame qui se renouvelle continuellement et dans lequel les seuls éléments réellement actifs sont les choses inertes» ${ }^{18}$ :

${ }^{17}$ La frase está tomada del programa político de El Día: véase Simone SAILlard, «Estudio preliminar», pp. 31-43, p. 35 .

${ }^{18}$ Lucien GoldmanN, «La Réification», en Recherches dialectiques, Paris: Gallimard, 1959 , p. 79, la cursiva es mía. 
Los que piensan que la crisis económica de estas provincias está vencida sin más que aprovechar el agua que cayó de las nubes, cambiarían de opinión bien pronto, si en vez de hacer conjeturas, tan fáciles como vanas, viniesen a este país y viesen... ¿qué? nada más que lo que salta a los ojos; la miseria que se exhibe por las calles. No se figure el lector que, en Córdoba a lo menos, el hambre anda amotinada, profiriendo gritos subversivos, ni pidiendo pan a las formas de gobierno; nada de eso; este pueblo es pacífico, como ya veremos tratando de su situación social más despacio; rara vez se subleva. Aquí la miseria de la clase jornalera, cuyo número se notará en los datos exactos que hemos de publicar, se manifiesta de otra manera; en forma menos alarmante que la sedición; pero en rigor no menos triste (II, p.151).

La personificación de la opinión pública parece ser la imagen complementaria de las personificaciones del hambre y la miseria, que paradójicamente no hacen sino impersonalizar el conflicto y presentar todo el aspecto humano de la cuestión social como una correlación de fuerzas autónomas que sólo pueden controlarse, o bien mediante un análisis que demuestre que la economía está en crisis, o bien a través de las instituciones pertinentes del Estado. Gracias a la ambivalencia de los conceptos, incluso el término abstracto de las personificaciones queda objetivado en la aparente evidencia de datos y cifras, que oculta pero no supera las separaciones irreductibles que subyacen a ella: la miseria, por ejemplo, llega a ser atributo de la clase obrera cuantificada («cuyo número se notará en los datos exactos que hemos de publicar») precisamente porque su referencia ideológica, tan amplia como abstracta, puede reconocer y designar desde fuera, identificándolas como un objeto exterior e indiferenciado, vivencias y experiencias sociales muy diversas ${ }^{19}$.

Lejos de reducirse a tomar una postura política, Alas trata de producir una comunidad entre sus lectores mediante mecanismos de identificación ideológica: por un lado, configura un campo específico de interés social y, por otro, intenta deliberadamente que su discurso se imbrique en la percepción de la sociedad y la actualidad que les supone a sus lectores, de modo que cada uno de los problemas evocados mediante personificaciones y figuras de evidentia quede despojado de toda singularidad problemática. La discontinuidad de las entregas, la presión de la actualidad y el fantasma del noticierismo ${ }^{20}$, son obstáculos que Alas trata de superar, primero, construyendo un escenario ideológico para su intervención pública y, después, diferenciando su discurso de todos aquellos que podrían confundirse con él. La fi-

${ }^{19} C f r$. Valentin N. Voloshinov, op. cit., pp. 118-137.

${ }^{20}$ La crítica del noticierismo no la desarrollará Alas hasta 1888, en «Teatro crítico. Un escritor, una firma» [La Justicia, 13-XII-1888], en Obras Completas VII (1882-1890), pp. 751-755. Es de notar que el artículo comienza equiparando el principio de que «se deben firmar los artículos de los periódicos» con el derecho al voto individual, en uno de esos paralelismos entre literatura y periodismo, por un lado, y economía y política representativa, por otro, que desde mediados de la década de 1880 van haciéndose cada vez más frecuentes en el discurso de Alas. 
gura del contribuyente parece haber hecho las veces de protagonista, por no decir de héroe, que intenta reconstruir la unidad social en un momento en que el proletariado empieza a definirse al margen de la legalidad burguesa ${ }^{21}$, y que cohesiona el discurso cuando las entregas pierden su regularidad y su periodicidad.

\section{LA ELOCUENCIA DE LOS NÚMEROS Y LA ECONOMÍA DE LA ESCRITURA}

Sin el apoyo empírico o positivo, las consideraciones generales de Alas sobre «la situación económica de las provincias» (V, p. 163) se dispersan en un confuso mosaico de «cuestiones que con este asunto se relacionan» (II, p. 154) y «asuntos» dentro de «esta cuestión» (VIII, p. 176), «muchos puntos que conviene estudiar según la casualidad [determine]» (III, p. 157), «antecedentes que pudieran ampliarse de modo indefinido» (IX, p. 182-183), etc. ${ }^{22}$ En sus formulaciones más claras, el objeto de estudio es la «situación que han creado en Jerez diferentes causas, que es preciso ir determinando en sus orígenes, hasta donde sea posible, y en sus relaciones» (VIII, p. 176). Y tan pronto como aflora en la argumentación de Alas un asunto concreto y singular, que no se deja reducir a las leyes abstractas de la economía política, su único punto de referencia es la elástica posición del contribuyente, en la que coinciden todas las esferas del problema.

Ahora bien, las constantes referencias de Alas a lo que ya se ha dicho y a lo que todavía se ha de decir, las interminables recapitulaciones de aquellos principios generales que los propios números ya deberían estar diciendo, no son fruto exclusivo del descuido ni de la torpeza, sino de las deter-

\footnotetext{
${ }^{21} C f r$., a pesar de la ironía, la siguiente frase: «de aquí se deduce que el proletario es en Jerez el que debe ser gran contribuyente. Si no paga será porque no come. Y aun esto no lo tiene en cuenta el Fisco. Él necesita cobrar, haya o no consumo» (XVII, p. 212).

${ }^{22}$ En El hambre en Andalucía no faltan alusiones a la «elocuencia de los números» (XIV, p. 201) y a su importancia dentro del proyecto de Alas: «procuraré evitar la confusión que traería el ir tratando de los muchos puntos que conviene estudiar según la casualidad determinase, sin más orden que el desorden en que a mí llegan los datos que voy recogiendo» (III, p. 157); «a mí me consta que a disposición del ministerio de Hacienda estuvieron años y años (y en rigor en su poder están siempre) los datos que pueden ilustrarle en este punto, datos que, casi con los números y sus relaciones, están diciendo los nombres de los que ocultan riqueza territorial» (VI, p. 170); «necesitamos ordenar nuestros datos, publicar números, comparar, tratar cuestiones parciales» (ibid.); «tan corta diferencia se explica por las notas que publicaremos en nuestro artículo siguiente» (XII, p. 196); «quedábamos en demostrar, con los datos a la vista» (ibid.); «recogeré algunos datos que me merecen crédito» (XVII, p. 211); «a la hora en que estos datos se nos facilitan, la operación no había podido realizarse» (XVIII, p. 215). Cfr. también IV, p. 161; VII, p. 175; y XIII, p. 197 y 198. Sólo cuando se hace referencia a datos ya publicados por otros corresponsales encontramos fórmulas genéricas tales que «es sabido» o «como saben todos».
} 
minaciones del modo de producción de texto que he denominado escritura periódica. Para aclarar un poco la cosa, cabe comparar el final de la carta $\mathrm{XV}$, que marca la suspensión de los artículos durante unos dos meses, con el principio de la siguiente, por error rotulada con el número XVII: el veintinueve de abril, Alas anuncia que «insistiremos en este punto, considerándolo bajo otros aspectos, para venir a parar a la aplicación de tal materia, a la cuestión del momento para nosotros, la administración municipal en Jerez, la cual ofrece inconvenientes y defectos que son también parte muy importante en los males que venimos estudiando, y a cuyas causas, que como se va viendo, son muchas, queremos pasar rápida revista» (XV, p. 209); y el veintiocho de junio recapitula lo que ya estaba dicho en los siguientes términos:

Examinábamos en el último artículo las relaciones de la vida municipal en Andalucía y especialmente su aspecto rentístico. Hablemos hoy, ya concretamente, de lo que sucede en Jerez, antes de dejar de examinar la crisis local de una comarca, a que tantos artículos se han dedicado en esta serie. Para ver cómo agobia a esa localidad, hoy tan estudiada, el sistema contributivo que prescinde de tener en cuenta la vida municipal, recogeré algunos datos que me merecen crédito. Sacando, en cifras redondas, el término medio del último quinquenio, puede decirse que paga Jerez [...] (XVII, p. 211).

No es sólo que Alas escriba con prisa, ni que, viéndose muy ocupado en sus ocupaciones universitarias, decida abandonar la serie que había emprendido bastante entusiasmado cuatro meses antes, con la idea de publicarla como libro en la «Biblioteca Económico-Política» de El Día. El problema parece más complejo que eso, porque la abolición del presente de la enunciación, subsumido en lo ya dicho y en lo que queda por decir, comienza ya en las primeras cartas de El hambre en Andalucía, y afecta a toda la producción de texto, desde la intención expresa del autor y la percepción de su propia escritura, hasta la recepción de la serie fragmentada en entregas; de hecho, cuando anuncia que «en adelante» «nuestros artículos» serán «más frecuentes», para ajustarse a las exigencias de un periódico, Alas asocia directamente la frecuencia del texto con el orden argumentativo. Está en juego la parte de su trabajo que considera más específica y menos genérica: de ahí que reivindique la exclusividad de sus datos y la amplitud de miras de su enfoque, y de ahí que insista en que quien habla, aunque no firme, no es un corresponsal más... y no es menos que un Peris Mencheta (que sí firmaba sus crónicas, publicadas más o menos al mismo tiempo en La Correspondencia de España) ${ }^{23}$.

Es esta tensión la que le da consistencia a la primera persona enunciativa

${ }^{23} \mathrm{La}$ inquina de Alas hacia Peris Mencheta queda documentada, como indica Simone SAILlARD («Leopoldo Alas, 1882-84: el tiempo de La Regenta», p. 123 y n. 6), en los artículos que publica en los números de El Día del 9, el 13, el 19 y el 26 de octubre de 1882 . 
que descuella insistentemente, en medio de las formas tópicas de la modestia periodística, en las cinco primeras cartas (sobre todo en la primera y en la tercera): al contrario que la mayor parte de los corresponsales, el «autor de estas cartas» no sólo emprende la serie «hablando de sí mismo» y distanciándose del medio en el que escribe, sino que incluso se reconoce una entidad pública anterior a la colaboración en El Día y anuncia que sólo hablará «de aquello en que podamos convenir periódico y corresponsal», «sin perjuicio de decir en otra parte» lo que haya de callarse ahora (I, pp. 147 y 148). Si no me equivoco, es una de las primeras veces que Alas afirma tan tajantemente una personalidad y una persona pública que preceden al proceso de escritura y que no tienen por qué identificarse por completo con sus cauces de publicación. Su última palabra es la interrupción provisional de la serie entre el veintiocho de enero y el veinticinco de febrero, que tiene algo de reapropiación del texto y del proceso de su producción:

\begin{abstract}
Ahora bien; si el orden natural exige que se trate primero de la producción y de su modo, según el país de que se habla, ya sabemos que este primer capítulo en Andalucía ofrecerá poca variedad, pero no por esto menos detenimiento, porque la complejidad que ya hay en la industria, considerada técnicamente, hace, $[s i c]$ el atender a las relaciones económicas de ella, en la distribución principalmente.

Pensando en lo cual, me aconsejó la prudencia suspender algunos días estas correspondencias, hasta ver en conjunto la manera de vida económica y de la producción, especialmente, de este país; y después de recorrer las varias provincias que comprende, he visto que no bastaría ir haciendo la reseña parcial del estado económico social de cada una, sino que antes era necesaria una consideración general de aquellas condiciones que le son comunes ( $\mathrm{V}, \mathrm{p} .164)$.
\end{abstract}

La crisis se manifestará, igual que en la producción material, en la yuxtaposición simultánea y violenta de los diversos momentos de la escritura, que se habían desgajado en distintas fases con funciones específicas y especializadas, situándose los unos al lado de los otros: en la medida en que está destinado a servir de material para otra fase diferenciada de la producción de texto, que es la única que llega a hacerse pública, el trabajo concreto de la documentación y la recogida de datos y cifras queda desprovisto de significado, porque se va acumulando sin dar lugar a interacción social; escindida de todo el proceso que lo ha generado, la escritura del original definitivo se presenta como el momento crucial, por no decir el único, de la producción de texto. La trastienda y el escaparate quedan entonces definitivamente separados por el mostrador donde se hacen los negocios: la recopilación de un sustrato documental (los cuadernos y carnets de notas en unos casos, los borradores y esbozos en otros) se convierte en un atesoramiento que interrumpe, difiere o impide la responsabilidad cívica de la prensa y la literatura, generada y amplificada en el debate, que es la revalorización constante del texto mediante su circulación, reimpresión y comentario público. 
Acaso no sea casual que en medio de esta crisis de valores se multipliquen en el discurso de Alas las referencias a «los tormentos de la usura» «antieconómica», hasta llegar al excurso contra la usura de la vigésima carta, publicada en El Guadalete el siete de julio y el ocho en El Día ${ }^{24}$ : si la acumulación de dinero contiene su circulación en el mercado e impide que se convierta en capital, el atesoramiento de documentos que no llegan a hacerse públicos devalúa el debate porque limita el intercambio de opiniones e ideas. Vistas a esta luz, cobran un sentido más profundo las dificultades enunciativas y la confusión que se reconocen a partir de la carta duodécima, justo al mismo tiempo que Alas empieza a sacar y a intentar comentar los datos y cifras que recopiló unos meses antes, durante su viaje por Andalucía. Cuando retoma la serie en junio de 1883, tras el atropellado cierre de la carta del 29 de abril, proliferan las recapitulaciones de cuanto se ha dicho, los anuncios de cuanto se ha de decir y, en última instancia, las justificaciones de lo que se está diciendo y del propio hecho de seguir diciendo, que remiten constantemente el discurso a cuestiones generales que nunca se tratan, en nombre de unos datos que se yuxtaponen torpemente en cada artículo: «difícil es la cuestión, y no cabe resolverla en general: la pasión sí las resuelve, unas veces culpando a la apatía, a la flojedad del espíritu andaluz, otras veces culpando a la clase obrera mal acostumbrada, otras veces exagerando los inconvenientes de la emigración y esclavizando por completo a los jornaleros» (XIX, p. 220); «antes de ver los vicios de que adolecen, la distribución del territorio y la manera ordinaria del cultivo, conviene hacer algunas observaciones generales acerca de la distribución natural de la población y la industria» (XX, p. 221); «decía en el artículo anterior que los errores del terrateniente no sólo hacían daño a sus intereses, por las razones indicadas, sino que venían a ser ruina del país entero. Nada más exacto y basta indicar la causa de ello, porque es obvia» (XXI, p. 224).

\footnotetext{
24 «En esta situación, que es muy general, todavía el error económico es mayor, porque no existiendo el crédito agrícola en las condiciones que serían necesarias para hacerle ser ayuda de la industria respectiva, el único medio de que se adelanten capitales al agricultor es el de la usura antieconómica, en la forma sórdida que se usa donde quiera que el crédito no está desarrollado en instituciones bien organizadas y de normal movimiento. La usura es, en efecto, la mayor plaga de la agricultura andaluza. El usurero es el ratón de campo, que se come las raíces de toda planta: más terrenos deja secos el usurero que las sequías. La codicia hace al propietario o al labrador arrendatario cultivar grandes porciones de terreno, recurrir al anticipo de la usura y no ver que los intereses enormes que se le exigen no pueden ser compensados por la renta del capital-tierra que es inferior, por ley natural en nuestras sociedades, al interés de toda industria, cuanto más al extraordinario interés de la usura sórdida, nacida del privilegio de la necesidad y el atraso de la vida económica» (XX, pp. 222-223). Para trazar la filiación de algunos de los argumentos de Alas, conviene recordar que en 1881 Camilo Hurtado de Amézaga y Balmaseda había publicado en la «Biblioteca Económico-Política» de El Día un folleto sobre El crédito agrícola: véase Simone SAILlARD, «Estudio preliminar», pp. 109-125.
} 
A la tensión entre los distintos momentos de la escritura hay que añadirle el posible desajuste entre el tiempo de la escritura, con todo lo que implica, y el tiempo de la publicación y la lectura, que es el que determina decisivamente la fortuna pública del texto. Un ejemplo elocuente es la transición de la segunda carta a la tercera, que salen en dos días consecutivos, el domingo siete y el lunes ocho de enero de 1883: la primera y la segunda se habían publicado en domingo, como si les correspondiera una sección fija o, cuando menos, un espacio tipográfico definido; en cambio, la tercera aparece un lunes y comienza con una extensa recapitulación que, desde el punto de vista de la lectura, resulta totalmente innecesaria:

En mi carta anterior, en que trataba (como en ésta y en algunas otras todavía) de las impresiones que recibe el que llega a esta tierra con ánimo de observar y anotar imparcialmente los fenómenos de la vida económica, en lo que se refiere a la actual crisis, comenzaba hablando de la miseria que salta a los ojos en las calles, pues se ve al pobre obrero demandando trabajo, como pobre a la puerta del convento, ante los umbrales de la casa del municipio. Incidentalmente, no por seguir orden riguroso todavía en la materia, hablaba de la viciosa conducta económica de estos trabajadores que, según la fama, prefieren el jornal exiguo al salario, porque el primero lo da quien no vigila bien el trabajo, quien no tiene interés personal en sus resultados. Pero añadía que si este error podía explicar algo de lo que aquí sucede en materia de producción y distribución, era preciso no creer que sólo a la clase jornalera hay que educar: [sic] errores económicos. En efecto, es necesario notar que las relaciones económicas en este país padecen males radicales que se pueden estudiar en todas las clases (III, p. 155).

Esta recapitulación revela una visión peculiar del público lector, porque apela muy directamente a su memoria de lectura y, sin embargo, reitera la mayor parte de las cosas que podría haber recordado; de hecho, al reiterar el proyecto y el orden argumentativo que ha elegido para realizarlo, Alas llega a presentar las anteriores entregas como pequeñas derivas dentro de un plan que ya tarda en realizarse. Aunque esta carta está escrita aún durante el tráfago del viaje, no es casual que el corresponsal de El Día vaya a insistir «en el método y en el tiempo necesario para aplicarlo» ${ }^{25}$ precisamente ahora que, tras salir a la luz las primeras acciones de la Mano Negra, la actualidad empieza a amenazar lo que le parecía el principal valor de su texto, lo más específico de su manera de ser escritor periódico:

Tomando este aspecto de generalidad, así en tiempo como en extensión, el asunto que me ocupa es necesario ordenarlo según sus elementos pidan, y procuraré hacerlo así, sin perjuicio de la claridad ni de la actualidad de mis correspondencias.

Sin pretender el riguroso método de un estudio didáctico, procuraré evitar la confusión que traería el ir tratando de los muchos puntos que conviene estudiar según la casualidad la determinase, sin más orden que el desorden en que

${ }^{25}$ Cfr. Simone SAILlaRd, «Estudio preliminar», pp. 127-140, p. 135. 
a mí llegan los datos que voy recogiendo. Por fortuna, la vida económica tiene un proceso natural, lógico, y ése será el que seguiremos, en cuanto sea posible, dado el carácter de estas indagaciones (III, p. 157).

Dando por buenas las fechas que encabezan las cartas, Alas escribe la tercera siete días después de la segunda, manteniendo en lo posible la frecuencia de una carta por semana, es decir, manteniendo la correspondencia entre el tiempo de escritura y el tiempo de publicación que había interiorizado en los tiempos de El Solfeo y La Unión ${ }^{26}$; a esa frecuencia le corresponde un margen de tres o cuatro días para el correo, y por ahora Alas sostiene el pulso. Al principio las cartas parecen destinadas a publicarse los domingos, como si formasen una sección fija y reconocible dentro del periódico; y quizás la tercera, enviada dentro de plazo o incluso un poco antes de lo previsto, se publicó inmediatamente para que El Día tomase parte, con información de primera mano, en un asunto que empezaba a estar en todos los periódicos, ganando así eco social, prestigio y ventas. No es imposible que, ante la evolución de los acontecimientos y su amplificación en la prensa, Alas quisiera cubrirse las espaldas insistiendo una vez más en que «el carácter» de sus indagaciones excluía toda veleidad noticierista, para marcar distancias con otros enviados especiales y darle a su texto un valor intransferible. Tampoco es imposible que su percepción de sí mismo y de su actividad se tambalease al ver que su texto, tantas veces proyectado, tantas veces postergado, había sido excluido de ese espacio periodístico privilegiado que es el fin de semana, y empezaba a circular fuera de su control inmediato, en condiciones decididas y determinadas por otros.

\section{FECHAS Y HECHURAS DEL TEXTO}

A la vista de las vicisitudes de la escritura de El hambre en Andalucía y de su publicación en El Día, podríamos preguntarnos qué ocurre con los textos que Alas recogió en un libro tras haberlos sacado en la prensa, cómo la yuxtaposición o recopilación de las entregas en un texto continuo produce un sentido diferente al que tenían en su primera publicación, y si en su concepto los lectores y las lecturas potenciales de un título son los mismos cuando este se publica en la prensa y cuando se publica, cierto tiempo después, en un volumen aparte. Quizás al escribir en varios lugares distintos, intentando adaptarse al carácter y la naturaleza de cada uno de ellos, Alas se figura (y configura) a un hipotético lector que, abriéndose paso en las apre-

${ }^{26}$ Cfr. Jean-François Botrel, «Introducción», en Leopoldo AlAS, Preludios de «Clarín», Oviedo: Instituto de Estudios Asturianos, 1973, pp. XII-LXXIII, especialmente XXVIIXXXVIII, y «Los años de aprendizaje» en Leopoldo AlAS Clarín, Obras Completas V: Artículos (1875-1878), ed. Jean-François Botrel e Yvan Lissorgues, Oviedo: Nobel, 2001, pp. 18-61. 
tadas columnas de periódicos y revistas, llegue a ser seguidor, luego aficionado, luego tal vez coleccionista de entregas y, al final, suscriptor de sus proyectos editoriales. Pero el proceso no está exento de rupturas y fisuras que merece la pena estudiar con detenimiento.

Cuando le ofrece «Avecilla», «Bustamante» y «El hombre de los estrenos» a Manuel Fernández Lasanta, para completar el tomo de Pipá, Alas recalca que «el primero se publicó en la Ilustración española hace tiempo, los otros dos poco menos que desconocidos pues los publicó la Ilustración ibérica de Barcelona, cuando era menos leída que ahora ${ }^{27}$. Por los términos en que pondera la novedad y la exclusividad del género, muy en su papel, parece que el público potencial de su libro podría coincidir en buena medida, sea en su concepto, sea en el de su editor, con la gente que «ahora» lee La Ilustración Ibérica — pero que no la leía necesariamente cuando, recién fundada, publicó primero «Avecilla» y después «Bustamante». El valor de los tres cuentos radica, pues, en que los posibles lectores y compradores del libro (ya) no los tienen en mente, bien porque el tiempo ya ha diluido su memoria de lectura, bien porque seguramente no llegaron a conocerlos (completos) en su primera encarnación. Lo fascinante del caso es que, en el paso del periódico al libro, Alas no introduce ningún cambio en los textos, y ni siquiera parece eliminar de ellos los rastros visibles de la escritura discontinua; planea y construye el volumen, incluso en el sentido más literal, con los materiales que ha ido sacando en la prensa:

Tengan mucho cuidado con que no se extravíe ninguno de los papelitos con que a veces va el original, porque yo no sabría dónde encontrar otro. Para evitar confusiones cada papel lleva el número de orden, como las páginas de un libro. En Avecilla notará Vd. que faltan las páginas 17 y 18; es que me falta un número que he mandado que me remitan de Barcelona y se lo enviaré enseguida ${ }^{28}$.

La imagen de un original hecho de retazos de periódicos y revistas numerados «como las páginas de un libro» da una idea muy gráfica del método de trabajo de Alas, pero también plantea ciertas exigencias de lectura y sugiere nuevas interpretaciones de los cuentos que nos ocupan.

La aparición de las once entregas de Los transeúntes.— «Avecilla», de extensiones muy irregulares, se dilató durante casi ocho meses, de enero a septiembre de 1883. Pueden reconocerse en ella cuatro ciclos bien diferenciados de escritura y publicación, en cada uno de los cuales Alas mantiene el ritmo semanal de la revista: entre el 6 y el 20 de enero publica tres entre-

${ }^{27}$ De la carta citada en la n. 8, p. 20. Cfr. todavía, en referencia a los artículos de Mezclilla, la carta fechada en Oviedo el 29-vII-1888 (ibid., pp. 39-42): «tengo reunidos muchos artículos de crítica seria y otros ligeros, de estos menos, voy a publicarlos, pues han sido muy poco leídos (¿quién lee La Justicia, La Publicidad y la misma Ilustración ibérica?) y son de lo menos malo que he hecho en estos últimos años» (p. 41).

${ }^{28}$ Ibid., p. 20. 
gas, cuatro entre el 16 de junio y el 7 de julio, y de nuevo tres entre el 25 de agosto y el 6 de septiembre; en los meses de enero a junio, que son también el momento crítico de El hambre en Andalucía, sólo aparece una entrega, el 19 de mayo ${ }^{29}$. Todas ellas están construidas como cuadros más o menos autónomos, que resultan inteligibles y tienen sentido fuera de su situación argumental pero que, ensamblados, retratan a un personaje en sus dimensiones pública y privada, funcionarial y doméstica ${ }^{30}$.

El primer ciclo de publicación, que va del 6 al 20 de enero de 1883, se distingue de los otros por un detalle curioso, y es que la extensión de las tres entregas que lo componen va disminuyendo visiblemente de semana en semana, hasta el punto de que la tercera ocupa poco más que la mitad de la primera. Podría pensarse que Alas escribió en principio dos entregas y, al ver que la segunda era bastante más larga que la primera, la cortó en dos para adelantar trabajo con vistas a su viaje a Andalucía; pero también cabe la

${ }^{29}$ Agradezco al profesor Jean-François Botrel la información sobre la extensión y la fecha de publicación de cada entrega en La Ilustración Ibérica. Las detallo a continuación, indicando entre paréntesis las páginas correspondientes en la edición de Carolyn Richmond, por la que cito siempre. «Avecilla» (pp. 214-234): «Don Casto Avecilla había pasado... lo mismo que su padre» (pp. 214-216), 6-I-83; «Decía antes que iba don Casto... sobre todo cuando le faltaban argumentos» (216-217), 13-I-83; «Vengamos al día... y ninguna sospecha nada._-iAbramos!» (217-218), 20-I-83; «¡Él era!... Vamos al teatro» (218-221), 19-V-83; «Vencidos los últimos escrúpulos... y Pepita sale con la corbata de su padre entre manos» (221-223), 16-VI-83; «Don Casto contempla a su hija con melancolía... — ¿En qué quedamos, papá?» (223-225), 23-VI-83; «El entusiasmo artístico de don Casto... formas abultadas de mujer gorda y desnuda» (225-227), 30-VI-83; «Ausentóse de aquel sitio la honrada familia... en cuanto a la gordura o profundidad» (227-228), 7-VII83; «Esta vez triunfó el amo de la casa por completo... menos culta que bien intencionada» (228-231), 25-vIII-83, con indicación de que «(Se continuará)»; «Salieron los Avecilla abochornados... en la pantorrilla de Mlle. Goguenard» (231-232), 1-IX-83, con indicación de que «(Se continuará)»; «Don Casto se acostó sin quitarse la corbata... ¡Si hubiéramos ido a la Zarzuela!» (232-234), 6-IX-83.

«Bustamante» (ed. cit., pp. 269-289): «iPero, señor, si él no lo negaba, si ya sabía que tenía razón su mujer!... que de Gibraltar a Madrid» (269-271), 10-v-84, con indicación de que «(Se continuará)»; "Ahora sí, eso de que habían de estar mal los romances... ¡Así esperó la hora de ser presentado a los satíricos del Bisturí» (271-274), 17-V-84, precedido del epígrafe «(Continuación)»; «Cuando Miguel Paleólogo Bustamante... Aquí hay que darse tono» (274-276), 21-VI-84, con indicación de que «(Se continuará)»; «Y acercándose a Rueda otra vez... - - Si comiéramos en el Inglés?» (276-280), 30-VIII-84; «La proposición fue aprobada por unanimidad... una cita de primeras letras» (280-283), 18-X-84; «Blindado y Miguel Paleólogo... de que ya dimos cuenta a nuestros lectores» (283-286), 6-XII-84, con indicación de que «(Se concluirá)»; «Los primeros días de su destierro en Guadalajara... «PALEÓLOGO»» (286-289), 27-XII-84.

${ }^{30}$ Cfr. Yvan LisSORGUES, «Estudio preliminar: las narraciones breves de Leopoldo Alas», en Leopoldo ALAS, «Clarín», Narraciones breves, Barcelona: Anthropos, 1989, pp. 7-51, especialmente 17-21; y Carolyn RICHMOND, «Aproximaciones a la narrativa breve de Clarín», en Leopoldo AlAS Clarín, Obras Completas III: Narrativa breve, ed. Carolyn Richmond, Oviedo: Nobel, 2003, pp. 7-88, especialmente 55-58. 
posibilidad de que, apremiado por los plazos, redujera sobre la marcha la extensión de cada entrega, hasta llegar a una especie de mínimo enunciativo en la del 20 de enero. Lo interesante del caso es que las entregas no se limitan a continuar las anteriores en un desarrollo más o menos lineal, sino que las corrigen, reformulando y reorientando uno o varios de los aspectos en ellas contenidos, para abrirle nuevas perspectivas al relato y sacarle más partido, o simplemente para encauzarlo: así, la segunda entrega parece poco más que una reescritura de la primera, un replanteamiento de la cuestión desde el punto de vista de lo habitual, o sea, del tiempo continuo de la vida que una tarde «de las primeras frías de octubre» se verá alterado por «una copa de Valdiñón» y por un proyecto que se le había metido «entre ceja y ceja» a don Casto Avecilla.

Ambos elementos, el vino y el tal proyecto, habían aparecido fugazmente en la entrega del 6 de enero: es el vino lo que hace que don Casto vea de color rosa incluso la tinta de las minutas, es esta impresión la que le mueve a preguntarse «¿quién ha traído esta tinta tan clara?» y añadir «es bonita para cartas de lechuguinos, pero no es propia de la dignidad del Estado», y es el uso de este término lo que mueve a la voz del autor ${ }^{31}$ a «advertir de paso, que Avecilla, muchos años después de haber comenzado su vida burocrática, había averiguado que lo que él había llamado el Gobierno siempre, no era precisamente quien le pagaba ni a quien él servía» (p. 214, la cursiva es mía). En apenas tres líneas, mediante un mínimo comentario hecho de paso, se desencadena y se resuelve la entrega, como si Alas, llevado por una idea que se le ocurre en el momento, cambiase sobre la marcha el plan que hasta entonces había ido preparando.

El 13 de enero aparece dos veces la imagen de don Casto rezagado durante el paseo «para considerar su personalidad jurídico-administrativa a sus anchas» (p. 216), que ya había aparecido, casi en los mismos términos, en el texto de la semana anterior. En cada uno de los tres párrafos que forman esta segunda entrega hay una alusión a lo ya dicho, a lo ya publicado, como si la voz del autor llamase la atención sobre las dificultades del escritor en la producción de su original: «decía antes que iba don Casto con su mujer y con su hija a paseo» (p. 216), «en cuanto a él, don Casto Avecilla, era, como dejo dicho, una rueda de la maquinaria administrativa» (ibid.); y al llegar al tercero, añade irónicamente que «iban delante su mujer y su hija Pepita, y él quedábase atrás, como ya dije dos veces; poníase el sol en el ocaso, como suele» (p. 217). A partir de ahí Avecilla entra en sus diatribas sobre su importancia en cuanto ruedecilla administrativa, que concluye cuando siente un

${ }^{31}$ Uso el término voz del autor estrictamente en el sentido que le da Mijaíl M. BAJTín, Problemas de la poética de Dostoievski, Madrid: Fondo de Cultura Económica, 2004 (reimp. de la $3^{\text {a }}$ ed.), pp. 264-298. 
poco de frío y se abrocha el gabán «para que una pulmonía no venga a interrumpir el juego de las instituciones» (p. 217).

Estas vacilaciones y reorganizaciones, más habituales de lo que parece, pueden dar lugar incluso a ligeras contradicciones y a resoluciones cuando menos convencionales: por ejemplo, hacia la mitad de la entrega del 19 de mayo, cuando empieza a agotarse la parodia de los argumentos de don Casto para convencer a su mujer, Alas introduce el contraste entre el carácter fantasioso de aquel y de Pepita y el menos imaginativo de doña Petra. Entonces la voz del autor alude de pasada al «secreto deseo» de doña Petra, que era «volver a ver las figuras de cera» (p. 220); y apenas ocho líneas más abajo anuncia, hablando en primera persona, como si acabase de descubrir un filón dentro de su propio discurso, que «aunque ella oculte el deseo de que hablo, porque sabe que a su marido le parece indigno de la esposa de un Avecilla, bien recuerda don Casto el placer intenso que experimentó Petra en Zaragoza durante las ferias de la Pilarica, contemplando la exposición de

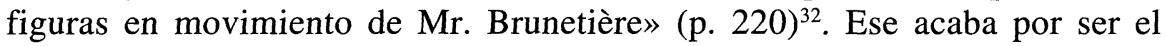
asunto principal del resto de la entrega, que tras desarrollar la diferencia entre las figuras de cera y el teatro termina volviendo, una vez más, a la determinación aplazada de don Casto: «en fin, Petra, tú estás dispensada de tener ideas estéticas. Vamos al teatro» (p. 221).

Las reiteraciones y reescrituras son, pues, rastros de un cambio de plan, o del descubrimiento de un plan posible: mediante la segunda toma del paseo, en el texto del 13 de enero, se desarrolla y se explica, esta vez como rasgo definitorio en la caracterización de don Casto, su tendencia a tomar al pie de la letra «cuantas metáforas y alegorías andan por los lugares comunes de la retórica periodística y parlamentaria», viendo «los respectivos objetos en la forma material del tropo» (p. 216). Es como si Alas sólo hubiese descubierto o decidido en esta segunda entrega, quizás incluso de repente, cuál sería el rumbo de su cuento, y cuál el aspecto que podría cohesionar todas las facetas del protagonista y todas las entregas del cuento: entonces empieza a desarrollar más detenidamente la parodia del discurso de don Casto, que será el verdadero punto de mediación entre su vida doméstica y su vida pública (o así la considera él) de pequeño funcionario, hasta que se demuestre tácitamente, en su confesión final ante los otros escribientes, que son sus palabras las que hacen la inadecuación: «no se le dejó proseguir; ya no pudo en su vida explicar aquellas palabras, y quedó como artículo de fe en la oficina que don Casto Avecilla era como los demás, que tenía querida y era robusta» (p. 234).

La importancia de la parodia puede comprobarse de un modo muy gráfico, ya que Alas la acentúa en todos los finales de ciclo de lectura, antes de

32 Sobre los antecedentes de esta escena, $c f r$. Leonardo ROMERO TOBAR, «La etapa zaragozana de Clarín: biografía y creación literaria», pp. 85-88. 
suspender la narración durante cuatro meses, un mes o seis semanas: con el discurso más o menos mediado de don Casto terminan las entregas del 20 de enero, del 19 de mayo y del 7 de julio ${ }^{33}$. A lo largo de todo el cuento, no es sólo que don Casto hable raro, sino más bien que con sus grandes palabras intenta transfigurar su realidad y su situación, presentándolas como manifestaciones de principios grandiosos y haciendo de ellas el centro de todo un universo que parece amenazado: así es como magnifica su «vie sans drame ${ }^{34}$, y sólo así consigue abrirse paso en el texto de Alas. Podría verse en su trayectoria un fracaso del tipo social que encarna y cuestiona al mismo tiempo, porque sólo es capaz de considerar sus actos y sus necesidades en relación con alguna de las grandes categorías del discurso costumbrista: de ahí, por ejemplo, que cuando comienzan a caminar por la Puerta del Sol, en la entrega del 30 de junio, «al valor de gastarse doce o veinte reales, protegiendo el arte nacional», le suceda en su espíritu precisamente «una serie de reflexiones relativas a las ventajas del ahorro en las clases pobres» (p. 225). Al final del cuento, cuando don Casto se reafirma en su conclusión de «aquella maldita noche» gritando que «iLo barato es caro, lo barato es caro!... ¡Yo bien decía!», doña Petra se hará oír como nunca antes, repitiendo «cien y cien veces» su propia conclusión: «iSi hubiéramos ido a la Zarzuela!» (p. 234). Irónicamente, es en el lance final del texto cuando deja de tener la última palabra don Casto Avecilla.

${ }^{33}$ En el texto del 20 de enero parece que don Casto, que ha ido polemizando en su fuero interno todo el camino, sigue hablando por boca de su mujer y su hija, como si incluso las palabras de estas fueran las que él se figura para sí: «-¡Una cana al aire!gritará Pepita, que tiene el pelo negro como la endrina. Las canas de los pobres son los ochavos. Dejemos a don Casto colgado del cordón de la campanilla, jadeante, anhelando comunicar a sus queridas esposa e hija su resolución temeraria._-iTilín, tilín, tilín!... -Es él —dice Pepita levantándose. -Él — repite la madre, y ninguna sospecha nada. - iAbramos!» (20-I 83, p. 218). Los otros pasajes a los que me refiero son los siguientes: «-Figúrate, hija mía; anacronismo sobre anacronismo (Pepita no sabía lo que era esto); un tutunvulutun (totum revolutum), un vademecum (pandemónium)[,] una caja de Pandorga (Pandora), en suma... Allí [en el museo de cera] vi ¡horror! a don Alfonso XII, al poder moderador, vestido de capitán general, con su difunta esposa Mercedes, del brazo derecho y la reina Cristina del izquierdo, ambas en traje de boda. ¡Bigamia espantosa, cuyo ejemplo hubiera bastado para desmoralizar toda la administración!... Después Rita Luna codeándose con Julio Fabre, el Empecinado mano a mano con la Emperatriz Eugenia, Mariana Pineda, a partir un piñón con el obispo Caixal... y por último, Calderón de la Barca, con un libro encarnado entre las manos, un libro, hija mía, titulado, bien lo recuerdo, Voyage sur les glaces (como suena)... En fin, Petra, tú estás dispensada de tener ideas estéticas. Vamos al teatro» (19-V-83, pp. 220-221). «-Distingo, señora mía, distingo -dijo don Casto-. No es gigante en sentido longitudinal; pero has de saber, esposa mía, de aquí en adelante, que hay tres dimensiones: longitud o largo, latitud o ancho, y profundidad o grueso... pero grueso vale tanto como gordo, luego esa señora es gigante en sentido lato, o mejor diré, en cuanto a la gordura o profundidad» (7-VII-83, p. 228).

${ }^{34}$ Honoré DE BALZAC, «Lettre à Hyppolite Castille, l'un des rédacteurs de La Semaine» [abril de 1845], en Écrits sur le roman, ed. Stéphane Vachon, Paris: Librairie Générale Française, 2000, pp. 307-323, p. 314. 


\section{SE CONTINUARÁ, SE CONCLUIRÁ}

Hay, sin embargo, un rastro de la escritura que sí se pierde en el paso de La Ilustración Ibérica a Pipá, y son las marcas paratextuales que avisan a los lectores, en unos casos, de que el texto debería seguirse, aunque se detenga durante un tiempo indeterminado, y en otros, de que seguirá en las semanas inmediatas, en los próximos números del periódico: bajo la alusión a la continuidad del texto se escondía, en cierto modo, una apelación a la continuidad de los lectores y una suerte de compromiso con la revista, tanto más evidente cuando se anuncia que el texto «se concluirá». El uso de tales marcas puede dar pie a algunas conclusiones generales sobre la crisis de escritura de que he tratado en estas páginas, y vuelve a llamar la atención sobre las determinaciones históricas de quienes, empezando a comprender «que el lector miraba ya con hastío y desconfianza el se continuará de los novelones, y quería saborear de una sentada todas las emociones de un asunto ${ }^{35}$, buscaron soluciones de compromiso antes de reducir sus artículos-cuentos a una única entrega.

En la tercera entrega de «Avecilla», ya comentada, Alas anuncia por dos veces la inminente interrupción de su texto: la primera es con un comentario muy revelador en que el narrador levanta la pluma y dice ${ } i \mathrm{Oh}$, el alegrón que con esta noticia dio don Casto Avecilla a los suyos, artículo aparte merece, así como las vicisitudes de aquella noche consagrada al arte!» (p. 218, la cursiva es mía); la segunda es con un «se continuará» que abre, tras el punto y aparte del último párrafo, la incertidumbre del punto y final, que se prolongará durante casi cuatro meses. Alas vuelve a utilizar el mismo recurso en las entregas del 25 de agosto y del 1 de septiembre, con la diferencia de que ahora el relato se continúa y se concluye en tres entregas, en tres semanas consecutivas, en tres números de La Ilustración Ibérica. Este detalle tiene su interés porque, en los meses que nos ocupan, Alas parece haber ido interiorizando el ciclo de siete días en casi todas las facetas de su escritura; tanto es así que, en tres de los cuatro ciclos de publicación de «Avecilla», consigue enviar artículo durante varias semanas consecutivas, sin interrupción. Además, a lo largo del mes de abril las «Cartas» de El hambre en Andalucía se publican más o menos cada siete días, con alguna deriva ocasional que se corrige adelantando la siguiente: la décima segunda se publica el sábado siete de abril, la décima tercera el sábado catorce, la décima cuar-

35 Benito PÉRez Galdós, «Prólogo a Cuentos de Fernanflor» [1904], en Prosa críti$c a$, ed. José Carlos Mainer y Juan Carlos Ara Torralba, Madrid: Espasa-Calpe, 2004, pp. 223-227, p. 224. Recordemos que el protagonista de «González Bribón», breve relato incluido en Cuentos morales (1896), está «loco de contento» con lo que llama «el crack de la «novela larga»», porque «sus principales antiguos enemigos son «novelistas largos». (Él escribe cuentos)», en Clarín, Cuentos completos II/2, pp. 205-208, p. 206. 
ta el martes veinticuatro y la décima quinta, intentando volver a la regularidad de antes, el domingo veintinueve. Es como si la costumbre de escribir en semanarios o en suplementos y secciones semanales le hubiera creado una nueva periodicidad al escritor periódico.

Volviendo a «Avecilla», la advertencia del 25 de agosto también hace notar que el texto no termina ahí, que ese no es el final, como si en él existiese una ambigüedad de base que debiera ser resuelta desde fuera. Veamos ese final provisional, que corresponde al momento en que don Casto, doña Petra y Pepita salen abochornados del teatro:

Cogieron las mujeres sus abrigos y salieron a la calle, no sin que les acompañara el público de las alturas con ese castañeteo de la lengua con que se echa a los perros de todas partes y a los espectadores impacientes de los teatros, según moderna costumbre, menos culta que bien intencionada (p. 231).

Aunque ya se ha resuelto el hilo argumental que parece predominante, a saber, el fracaso del proyecto «pedagógico-cultural» de don Casto, todavía hay cabos sueltos en relación con las dos primeras entregas, donde ni siquiera se había mencionado el teatro, sino un vago proyecto inspirado por la ebriedad de Avecilla: de haber terminado ahí el cuento, habría quedado resuelto un aspecto, pero el marco fijado en las primeras entregas, escritas cuando quizás no estaba muy claro el argumento, se habría visto reducido a la función de punto de partida inerte. El texto del uno de septiembre, más ambiguo todavía, también podría concluir la historia, sólo que esta vez predominan la moralización irónica y la dimensión privada de don Casto, sus preocupaciones de padre de familia que empieza a temer la realización literal de sus palabras:

-Estoy resuelto, i[para no despertar a Pepita] Me acostaré con corbata y con camisa! ¡Yo, que no he consentido jamás que me hicieran dormir con ropa almidonada! ¡Pero, en fin, me sacrificaré! ¡Todo, antes que interrumpir el sueño de la inocencia! Porque aún será el sueño de la inocencia, ¿verdad, Petra mía?

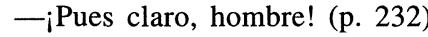

Parece lógico que Alas, temiendo un malentendido, prefiriese aclarar que el desenlace todavía estaba por llegar, porque, cuando fracasa el proyecto de ir al teatro, fracasan también todas las ilusiones de participación en la alta cultura y en «la esfera artístico-administrativa» (p. 218) que albergaba don Casto, y esto sí merece un desarrollo más allá de la anécdota. Mirando el conjunto del cuento tal y como se editó en Pipá, sin atender a la división en entregas, parece imprescindible la coda en la que, tras referir cómo Avecilla se pone en (falsa) evidencia ante sus compañeros de la oficina, se nos cuenta la desventura de Pepita en sus amores de infantería; mirándolo desde la lectura casi cíclica de las entregas, en cambio, resulta evidente que Alas advierte a sus lectores de que ese no es el final para tener él la última palabra. El aviso de que un cuento «se continuará» sirve entonces, por un lado, 
de acicate de la memoria y, por otro, de incitación al coleccionismo, como si la memoria de lo dicho hubiese quedado diluida en la dispersión del decir; por eso el sentido ha de fijarse a posteriori, en una forma concluida que el texto no tenía en el proceso de su producción.

Pero Alas no sólo utiliza este procedimiento de cerrazón discursiva en el final anunciado de los cuentos que publica, sino también, de modo mucho más sutil, en las transiciones entre entregas y en otros momentos críticos de la escritura. Analizando como enunciados autónomos las entregas de «Avecilla», me llamó la atención el hecho de que la transición entre el último párrafo de cada una y el primer párrafo de la siguiente era, en ocasiones, mucho menos abrupta y menos marcada, desde el punto de vista discursivo, que la transición entre el primer y el segundo párrafos de esta última: puede compararse, por dar un solo ejemplo, el final del texto del 19 de mayo con el arranque del publicado el 16 de junio, cuyo segundo párrafo apela bruscamente al lector, antes de saltar sin solución de continuidad del proteccionismo gramatical de don Casto a la descripción del tocador de Pepita ${ }^{36}$. Lo que está en juego es, en mi opinión, un aspecto crucial del oficio que desarrolló Leopoldo Alas Clarín para hacer frente a las crisis y las dificultades específicas de la escritura periódica, y así parece demostrarlo un análisis detenido de «Bustamante».

La mayor parte de las entregas de este cuento van acompañadas de señuelos paratextuales, que hacen notar que el texto de la semana es una parte dentro de un todo más amplio: la primera avisa de que «se continuará» y la segunda, publicada una semana después, va encabezada con el epígrafe «continuación»; la tercera, aparecida el 21 de junio, termina prometiendo una continuación que no llega hasta el 30 de agosto; la cuarta y la quinta, aparecidas el 30 de agosto y el 18 de octubre respectivamente, no llevan indicación alguna; y la sexta, del 6 de diciembre, promete una conclusión que se publica tres semanas más tarde. Esta vez Alas parece haber resuelto la falta de periodicidad haciendo entregas más largas y autónomas, que caracterizan al personaje Miguel Paleólogo Bustamante y desarrollan sendos episodios de su estancia en Madrid, desde la llegada en busca de una credencial o de una posición como «escritor satírico» hasta su exilio, «víctima de nuestras disensiones políticas», primero en Guadalajara y después en Andalucía. De

\footnotetext{
${ }^{36}$ Precisamente en este momento, según la interpretación de Laura DE LOS Ríos, «el cuento adquiere una nueva dimensión» $\mathrm{y}$ «entramos en un mundo que comienza a desrealizarse» (Los cuentos de Clarín, proyección de una vida, Madrid: Revista de Occidente, 1965, p. 41). Podrían aducirse otros muchos casos, entre ellos el final de la entrega del 6 de enero y el principio de la del 13: el primer párrafo de esta arranca enlazando muy directamente con el final de aquella («decía antes que iba don Casto con su mujer y con su hija a paseo...»), y apunta después una dirección alternativa para el desarrollo del cuento (la manía de don Casto con las palabras compuestas); pero el segundo párrafo no sigue esa dirección, sino que vuelve a la primera («considerando, pues, su personalidad, o dígase entidad, que lo mismo le daba a él, jurídico-administrativa»).
} 
hecho, en «Bustamante» se reconocen muchos menos rastros de la producción de texto que en «Avecilla», como si el mayor esquematismo del argumento permitiese componer entregas mucho más cerradas sobre sí mismas sin desmerecer el conjunto.

La impresión de cerrazón discursiva, casi de inmanencia, que transmiten las entregas se debe, creo yo, a la disposición de su principio y su final: por un lado, comienzan tan abruptamente que parece, según dice la voz del autor sobre el estilo de Merengueda, «como que se sigue hablando... de lo que no se había hablado todavía» (p. 275), y por otro, terminan siempre en un punto de interrupción, de modo que la escena queda cortada sin avanzar sus consecuencias ni dejar que se desencadenen los acontecimientos. Paradójicamente, estos cortes tan abruptos parecen ser la mejor advertencia de que el texto de hoy continúa una serie emprendida en números anteriores de la misma revista, unas semanas atrás; y el efecto de que una entrega no termina realmente hasta la siguiente llega casi a disolver la discontinuidad del texto, pautando y configurando desde la escritura sus lecturas posibles. Ocurre incluso que las ilaciones discursivas y las recapitulaciones formularias típicas de las narraciones discontinuas, entre ellas el consabido «como íbamos diciendo», no aparecen en el primer párrafo de cada entrega, sino en el segundo:

No ocultaba Bustamante que le costaba mucho trabajo hacer estos versos y otros por el estilo, y si no se hubieran inventado los ripios los hubiera inventado él para salir de tamaños apuros. Y aquí me permitiré una digresión relativa a la retórica y poética de este literato de su pueblo, digresión útil porque pinta la manera de matar versos que tienen muchos escritores de cabeza de partido. Bustamante, considerando que el escribir versos era operación que hacía sudar y llegaba a calentar la cabeza, creía, lleno de lógica, que el mayor mérito de un verso (vulgo poesía) estaba en que fuera muy grande; cuantos más renglones mejor. ¿No tiene más mérito un andarín que anda cinco horas sin descansar que otro que sólo ande tres horas? ¿No apuestan los andarines a quién aguanta más? Así era Bustamante, un poeta de resistencia; y así creía él que debían ser los poetas. El cambiar de metro se le antojaba una abdicación. Nada de redondillas (que además nunca le salían a derechas), romance y tente tieso; pero romance con un solo asonante (él no lo llamaba así) aunque fuese más largo el verso que de Gibraltar a Madrid. [(Se continuará)]

[(Continuación)] Ahora sí, eso de que habían de estar mal los romances si caían en copla completa (consonante) le parecía a Miguel una barbaridad, con permiso de Ruedita. El que las palabras acabasen con las mismas letras, exactamente, ¿no era mérito mayor? ¿No tenía más dificultad? Pues cuantos más consonantes en el romance, mejor. Sin saber por qué, prefería los romances agudos, porque el recurso de los verbos en infinitivo (si era en $a, e$ o $i$ el romance) le parecía muy útil, y cuando no bastaba eso, valía aquello de: Zas, ya, ¡tras!, ;ah! iquia! jvoto va! pues, jeh! ipardiez! en fin, grano de anis, ipor San Gil! y otras interjecciones y frasecillas por el estilo.

Bustamante, como íbamos diciendo, en vez de ir a la fonda de López buscó la posada de Rueda y sorprendió al literato estudiante en el lecho, tres horas escasas después de haberse acostado el autorcillo satírico, que trasnochaba, por no ser menos que otros (pp. 271-272). 
Lo cierto es que el primer párrafo de la segunda entrega parece más bien el último de la primera. Teniendo en cuenta que se publicaron con sólo una semana de diferencia, cabe la posibilidad de que Alas escribiera las dos entregas de un tirón, formando una sola mucho más extensa, y las enviara a La Ilustración Ibérica con la intención de publicarlas en el mismo número, el del 10 de mayo de 1884; podría pensarse también que es por ese motivo por lo que ambos textos llevan las indicaciones correlativas de «se continuará» $\mathrm{y}$ «continuación». Pero no parece muy verosímil, porque las dos primeras entregas, sumadas, formarían una unidad de escritura mucho más larga de lo que suele ser habitual en Alas, que en este momento debía de estar bastante atareado terminando la primera parte de La Regenta y cumpliendo sus otros compromisos ineludibles, como la serie sobre «Los poetas en el Ateneo» para El Día y las colaboraciones más salteadas en Madrid Cómico ${ }^{37}$.

La clave es, me parece, un truco propio de un escritor de oficio: probablemente Alas, abrumado por las imposiciones de la escritura periódica, le enviaba a su editor todo el original de que disponía, menos el último párrafo, que conservaría para utilizarlo como principio de la siguiente entrega y señuelo para recordar por dónde iba. Con sólo hojear sus epistolarios, especialmente las cartas a Sinesio Delgado, Fernando Fe y Manuel Fernández Lasanta, comprobamos que Alas no solía conservar el original de sus textos ni atesorar las entregas ya impresas de sus artículos-cuentos, ni siquiera de aquellos que estaban pendientes de continuación o conclusión; escribía, según su propia declaración, principalmente de memoria, y sin duda resultaría poco práctico y muy poco decoroso pedirle al periódico o revista de turno que le enviase las últimas entregas de sus propios artículos-cuentos cada vez que quisiera seguir con ellos o terminarlos. Además, el hecho de utilizar el último párrafo de una entrega (en el sentido de «unidad de escritura») para comenzar la siguiente podría darle una cierta continuidad, tanto material como intelectual, al proceso de producción de texto; casi podría pensarse que en el arranque de la escritura, tras ese párrafo que sirve de puente, va insinuada o esbozada la reacción que se espera provocar en la memoria del lector.

Las entregas de «Bustamante», tan poco periódicas, parecen haber sido escritas utilizando esa especie de hilván narrativo: por ejemplo, la del 21 de junio termina abruptamente cuando Miguel se da cuenta de que, si quiere quedar bien con los redactores de El Bisturí, va a tener que darse importancia, y la del 30 de agosto empieza, casi como si no hubiese habido interrupción, cuando le pregunta a Rueda «oye, tú, ¿qué opinan estos señores de López... el diputado de allá?». La pregunta encierra, en apenas dos líneas,

${ }^{37}$ Ya en marzo le promete a Galdós que «de Tormento hablaré en El Día en cuanto concluya unos artículos acerca de los poetas en el Ateneo» (carta fechada en Oviedo el 15-III-1884, en Soledad ORTEGA, pp. 213-216, p. 216), pero la reseña se retrasa, primero por problemas de escritura, quizás por desavenencias con el Marqués de Riscal después, hasta el mes de julio. 
varias referencias anafóricas que podían refrescarle la memoria al lector, pero también un señuelo para guiar la escritura y recordar, andando el tiempo, que ahora venía la «discusión política». Lo mismo ocurre en las entregas del 18 de octubre y del 6 de diciembre, que engarzan con las precedentes mediante un breve párrafo que recapitula los últimos acontecimientos $\mathrm{y}$, al mismo tiempo, insinúa un posible punto de partida: en un caso es la frase «la proposición fue aprobada por unanimidad, pero se le impuso una condición a Bustamante: que no había de pagar él por todos» (p. 280), que alude al desenlace de la entrega anterior y al episodio del café, donde había pagado Miguel, y apunta la posibilidad de desarrollar en una escena cómica las falsas disuasiones de Ruedita, Blindado y Merengueda; en el otro es un breve párrafo que recuerda la conversación de los estudiantes-periodistas en el Café Inglés y avanza la visita de Paleólogo y Blindado a ciertas señoras conocidas de este, aunque al final van al Teatro Real y Bustamante acaba detenido: «Blindado y Miguel Paleólogo quedaron en que la moral era relativa y en ir aquella noche a visitar a varias damas de las Camelias, irredimibles y hasta empeñadas» (p. 283).

Los episodios van ensartándose en el tiempo casi cíclico de la aventura de un provinciano en Madrid, al que Alas da salida con la prisión y posterior exilio de Miguel, «entre otros estudiantes» (p. 286). El texto del 6 de diciembre y el del desenlace, publicado el 27, van unidos por el anuncio explícito de que «se concluirá»: si el primer párrafo de la conclusión hace referencia a lo que tres semanas antes decía una supuesta noticia de $\mathrm{LaCO}$ rrespondencia, presentando ya la frase que articulará el final del cuento («su carácter de víctima de nuestras disensiones políticas le tenía muy orgulloso y descontentadizo»), el segundo, el tercero y el cuarto introducen muy abruptamente unos pasajes de las memorias de Paleólogo, por ahorrar una narración que ya podría hacerse pesada:

\footnotetext{
La Correspondencia lo decía: «Don Miguel Bustamante, alumno de la facultad de Medicina; Don Pedro Pérez, de la de Farmacia, y Don Antonio Gómez, de las de Ciencias, han sido desterrados a Guadalajara, a consecuencia del escándalo del Teatro Real, de que ya dimos cuenta a nuestros lectores». [(Se concluirá)]

Los primeros días de su destierro en Guadalajara se aburrió mucho Miguel Paleólogo. Su carácter de víctima de nuestras disensiones políticas, le tenía muy orgulloso y descontentadizo. Hablaba poco con la patrona, nada en la mesa, iba al café y pedía su veneno correspondiente por señas, y sin decir una palabra pagaba.

Empezó a escribir sus memorias para entretener sus ocios.

Un extracto de aquel diario nos ahorrará muchos párrafos de soporífera narración.

Copio: [...] (p. 287).
}

Esta parece ser la única salida posible para concluir el texto, y no es de extrañar que Alas avisase de que todavía iba a hablar de nuevo, esta vez para 
terminar: si lo que se cuenta en «Bustamante» es la conversión casual del poeta festivo Miguel Paleólogo Bustamante en periodista y exiliado político, el proceso estaría incompleto si no llegásemos a oír su voz nueva, que contrasta con las charadas del principio y, lo que es más importante, con el silencio literario que le caracteriza mientras está en Madrid ejerciendo de literato. Al introducir unas páginas del diario de su protagonista, combinadas con notas de prensa atribuidas a La Correspondencia, Alas clausura, mediante dos voces que no son la del autor, la sucesión de episodios que ha ido llenando el tiempo del protagonista, ahora todo memoria y ocio; tal vez por eso resuenan irónicamente en el desenlace del cuento, tan poco heroico, los ecos de una fórmula periodística que por entonces hacía fortuna en otras páginas, en otras columnas de otros periódicos, a saber, la designación de los exiliados como «víctimas de nuestras disensiones políticas».

Quizás la historia de ese gran hombre de provincias ya talludito en Madrid, con sus aventuras entre estudiantes metidos a periodistas, con los lances del restaurante y del teatro, pudiera integrarse más directamente que la de «Avecilla» en el horizonte ideológico de su público, en su experiencia de lectores y en su conocimiento compartido de los códigos de la prensa. Así cabría interpretar las interpolaciones, en las dos últimas entregas, de supuestos breves de La Correspondencia, que cuentan con perspectiva totalmente exterior (y alarmismo creciente) las detenciones de Bustamante y sus distintos secuaces: Alas concluye y cierra su historia, que podría haberse perdido en una insulsa narración en sarta, utilizando un discurso periodístico que sus lectores sin duda reconocerían, y que podría darles la medida real del personaje y de sus aventuras. Casi parece que está inventando, mediante una palabra ajena que se impone a todas las demás, la genealogía posible de un breve, y desvelando lo que puede haber detrás de esos textos que a diario aparecen en los periódicos; de hecho, el final invierte todo el proceso precedente del cuento, que narraba las aventuras del personaje en un tiempo casi cíclico, y lo proyecta sobre el terreno de la actualidad, sobre lo que ya se ha convertido en «el escándalo del Teatro Real, de que ya dimos cuenta a nuestros lectores» (p. 286). Es así, mediante la palabra ajena, como Miguel Paleólogo Bustamante llega a adquirir toda su dimensión de transeúnte, y es así como Alas consigue concluir semánticamente la narración.

\section{CONCLUSIÓN}

Hemos visto las distintas determinaciones de la escritura periódica, según se manifiestan en las cartas sobre El hambre en Andalucía y en los cuentos de Los transeúntes. Dentro de esta problemática general, he intentado reconocer en cada texto los rastros, no siempre evidentes, de su producción, las tensiones ideológicas que revelan $\mathrm{y}$, sobre todo, las soluciones prácticas 
que Alas, escritor de talento y oficio, les busca y a veces les encuentra: así he interpretado el repentino protagonismo de la figura del contribuyente, que a menudo es el único medio de que dispone nuestro autor para introducir, en un discurso de por sí problemático, las cifras y datos que no acaban de encajar en el plan que había concebido para organizar su texto discontinuo y superar, por decirlo así, las constricciones de la escritura periódica dentro de la propia escritura periódica.

En las cartas de El hambre en Andalucía fracasan técnicas de escritura discontinua que funcionan sin mayor problema en «Avecilla»y en «Bustamante», y el motivo de ese fracaso puede buscarse en la interposición de un sustrato de letra muerta en la escritura. Casi ningún aspecto podría minar más profundamente la práctica de producción de texto de un escritor como Leopoldo Alas Clarín: el ansia de publicidad, que confiere un carácter social a la actividad íntima (o percibida como tal) de producir original, quedará interrumpida e impedida por los datos y las cifras, es decir, por la expresión elocuente de aquellas verdades que pretendía revelar y poner en circulación. Esta es una de las manifestaciones más complejas de la crisis de su escritura pública, y quizás una de las experiencias que más determinaron el proceso de redacción y conclusión de La Regenta. Leyendo El hambre en Andalucía, a veces tenemos la impresión de que cada carta reescribe y corrige las ya publicadas, como si las columnas del periódico ya impreso fueran unas galeradas que todavía pueden rectificarse y adecuarse a la estrategia expositiva elegida: no muy lejos queda la imagen de Leopoldo Alas Clarín redactando La Regenta contra el reloj de las pruebas de imprenta, estructurando su «tiempo de novelar» según la experiencia adquirida en la escritura periódica.

Con la lectura a contrapelo de las entregas de «Avecilla»y «Bustamante» he querido mostrar cómo la escritura discontinua puede reorganizarse sobre la marcha, hilando y deshilando el texto según las ocurrencias del momento, y concluirse después, mediante diferentes procedimientos, en un sentido objetivado que no tiene por qué ser el producido en la sucesión de las entregas. La forma de ambos cuentos, con todas sus ambigüedades, es inseparable del modo de producción de texto y de publicación en que fueron realizados, y quizás la mejor prueba sea el hecho de que persisten en ellos, aunque disimulados por la lectura del cuento como un único texto continuo, los rastros de la escritura que he comentado en el presente trabajo. En este rastreo han ido apareciendo, en una unidad indisoluble, distintos aspectos del arte verbal y del oficio de Alas, que tal vez puedan utilizarse en futuras lecturas de otros artículos-cuentos y, llegado el caso, en el análisis de otras obras más extensas. Es más, quizás también habría que comparar los textos que nos han ocupado con los de la época de El Solfeo y La Unión, para calibrar mejor las diferencias entre la escritura del redactor polivalente que fue Clarín, con todos sus seudónimos, en aquellos dos periódicos, y la del escritor periódi- 
co que será a partir de 1882. Las condiciones no pueden ser las mismas cuando la presencia pública de un autor se identifica casi exclusivamente con un único periódico, ejerciendo de redactor polivalente a diario, que cuando cada colaboración es una entre otras muchas y está destinada a producir un tipo de texto específico y determinado a priori.

Mirado en un sentido más general, el análisis aquí desarrollado ofrece una última conclusión, ya de mayor calado, sobre la relación de la escritura periódica con la actualidad. Esta suele aparecer explícitamente en el discurso de Alas como una veleidad de la mala prensa, poco ilustrada unas veces, demasiado sensacionalista otras, irresponsable siempre, y llega a ser una amenaza no sólo para el orden que se había propuesto seguir en su rigurosa exposición sobre la situación de Andalucía, sino también para el propio concepto de armonía social que pensaba explicar y propugnar. Pero, como se comprueba en una lectura atenta de «Bustamante», la actualidad es también un territorio ideológico compartido con el lector: hace inteligible la continuidad entre las entregas a base de sobreentendidos, y puede cerrar semánticamente un discurso que, en su carácter aparentemente no teleológico, encierra una afirmación previa de todos los fines y todos los finales de la ideología. Al contrario que los de El hambre en Andalucía, los textos de Los transeúntes no toman el discurso del «periodismo de actualidad» como un contenido, sino como un material, y nunca invocan ni avanzan un plan previo desgajado del proceso mismo de su escritura; se marcan así, ya desde la misma enunciación, las distancias entre el texto de Alas y aquellos con los que puede coincidir en la plana de un periódico, en la mesa de un casino o de una casa, o incluso en la memoria de los lectores: el discurso dice y hace, afirma y construye su especificidad en un único gesto indisoluble. Tal vez sea esta la conclusión más importante que puede aportar el presente trabajo a la crítica de la obra de Leopoldo Alas Clarín. 


\title{
RESUMEN
}

El escritor periódico: Leopoldo Alas 'Clarín', 1883-1884, por Santiago Díaz Lage.

Mediante una lectura de la serie de artículos El hambre en Andalucía y de los cuentos de Los transeúntes («Avecilla» y «Bustamante»), analizo las técnicas de escritura discontinua que desarrolla Leopoldo Alas Clarín para cohesionar a todos los niveles un discurso producido y publicado por entregas. En este análisis parto del concepto de escritura periódica, con el que quiero definir el modo de producción de texto que se impone con la expansión de la prensa a lo largo de la década de 1880.

Palabras clave: Leopoldo Alas Clarín (1852-1901): crítica e interpretación.-El hambre en Andalucía, «Avecilla», «Bustamante».-Artículos y cuentos, Prensa y Literatura (siglo XIX).-Escritura periódica.

\begin{abstract}
By means of a reading of the article series El hambre en Andalucia and the short stories of Los transeúntes («Avecilla» and «Bustamante»), I examine the techniques of discontinuous writing developed by Leopoldo Alas Clarin in order to bind all aspects of a text produced and published in instalments. In this analysis I start from the concept of periodical writing, with which I want to define the mode of textual production that becomes dominant with the spread of journalism during the $1880 \mathrm{~s}$.
\end{abstract}

Keywords: Leopoldo Alas Clarín (1852-1901): criticism and interpretation.-El hambre en Andalucía, «Avecilla», "Bustamante».-Articles and short stories, Press and Literature (nineteenth century).-Periodical writing. 